\section{A Response to Douglas Jesseph}

\section{Amir Alexander}

The Mathematical Intelligencer encourages comments

about the material in this issue. Letters to the editor

should be sent to the editor-in-chief.

do not, in general, respond to reviews of my work, even critical ones. But Douglas Jesseph's review of Infinites-

imal: How a Dangerous Mathematical Theory Shaped the Modern World (The Mathematical Intelligencer, vol. 39, no. 1, March 2017) is so misleading that it cries out for at least a brief correction.

The errors in this piece are myriad: André Tacquet, far from being a friend of indivisibles, declared that they "make war" on geometry. When he proposed a related method that he believed might pass muster, he was immediately set right by the Jesuit Superior General. Roger Boscovich, the 18th-century Jesuit luminary, was not "an enthusiastic proponent of infinitesimal analysis," but rather a devoted Euclidean whose geometrical approach set him apart from the leading mathematicians of his age. And if John Wallis was, as Jesseph contends, a "traditional" mathematician who employed "unchallengeable demonstrative reasoning," one is left wondering what those words mean when applied to a mathematician who treated geometrical figures as quasimaterial objects, divided $\infty$ by $\infty$ when it suited him, and "proved" theorems through Baconian induction.

All of these specific errors, and numerous others, have their root in a core misunderstanding. Jesseph believes that the book argues that the struggle over infinitesimal methods was "actually" about politics, and that the mathematical debates were mere "window dressing." But one will search the pages of Infinitesimal in vain for any suggestion of such subterfuge. As the book makes clear, the contenders on both sides of the debate were fully convinced that theirs was the only mathematically correct position. It is just that for them the implications of their stance extended far beyond the technical aspects, to the proper order of the world, of religion, of the state. This knowledge did not diminish their commitment to their technical mathematical position, but immeasurably enhanced it.

Sometimes questions about mathematics are also questions about the world-whether, natural, social, or political. And that, as much as anything, is what Infinitesimal is about.

Department of History

University of California at Los Angeles

Los Angeles, CA 90095-1473

USA

e-mail: amiralex@ucla.edu 